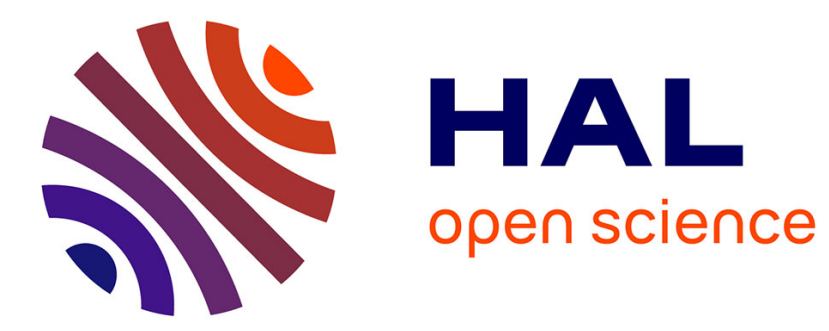

\title{
Modeling of void coalescence initiation and its impact on the prediction of material failure
}

\author{
Sabeur Msolli, Mohamed Ben Bettaieb, Farid Abed-Meraim
}

\section{To cite this version:}

Sabeur Msolli, Mohamed Ben Bettaieb, Farid Abed-Meraim. Modeling of void coalescence initiation and its impact on the prediction of material failure. 19th International ESAFORM Conference on Material Forming (ESAFORM 2016), Apr 2016, Nantes, France. 10.1063/1.4963549 . hal-02872239

\section{HAL Id: hal-02872239 \\ https://hal.science/hal-02872239}

Submitted on 17 Jun 2020

HAL is a multi-disciplinary open access archive for the deposit and dissemination of scientific research documents, whether they are published or not. The documents may come from teaching and research institutions in France or abroad, or from public or private research centers.
L'archive ouverte pluridisciplinaire HAL, est destinée au dépôt et à la diffusion de documents scientifiques de niveau recherche, publiés ou non, émanant des établissements d'enseignement et de recherche français ou étrangers, des laboratoires publics ou privés. 


\title{
Modeling of void coalescence initiation and its impact on the prediction of material failure
}

\author{
Sabeur Msolli ${ }^{1, a)}$, Mohamed Ben Bettaieb ${ }^{1, b)}$ and Farid Abed-Meraim ${ }^{1, c)}$ \\ ${ }^{1}$ LEM3, UMR CNRS 7239 - Arts et Métiers ParisTech, 4 rue Augustin Fresnel, 57078 Metz Cedex 3, France \\ DAMAS, Laboratory of Excellence on Design of Alloy Metals for low-mAss Structures, Université de Lorraine, \\ France \\ a) Corresponding author: Sabeur.Msolli@ensam.eu \\ b) Mohamed.Benbettaieb@ensam.eu \\ c) Farid.Abed-Meraim@ensam.eu
}

\begin{abstract}
In the present paper, Thomason's criterion is coupled with the well-known Gurson-Tvergaard-Needleman (GTN) damage model and used for the determination of the critical void volume fraction $f_{c}$, which marks the initiation of the coalescence stage. The onset of void coalescence predicted by Thomason's criterion is compared to that obtained by using a predefined $f_{c}$, which is usually fitted on the basis of experimental results, as originally proposed in the GTN model. Comparisons are made in terms of both single finite element simulations and numerical results of deep drawing of a cup.
\end{abstract}

\section{INTRODUCTION}

The prediction of the formability of sheet metal parts is a quite important task nowadays. Under severe forming operations, drawn parts are often exposed to failure due to crack initiation and propagation. Among the key mechanisms that are likely to promote the occurrence of cracks, one can quote the nucleation, growth and coalescence of voids in the sheet material. The degradation is also compounded by the presence of initial defects or initial void volume fraction. At the coalescence stage, a drop in the material stiffness is recorded and failure proceeds. In order to describe the material behavior, dependent on the evolution of void volume fraction, several models have been developed in the literature. Gurson-Tvergaard-Needleman (GTN) model may be considered as one of the most popular damage models [7]. It has been applied for the modeling of material damage behavior from nucleation to coalescence and proved its efficiency in many applications. This model has also been extended to account for kinematic hardening [2] and has been used to predict the ductility limit of thin metal sheets [4]. However, issues relating to the critical void volume fraction $f_{c}$ still rely on experimental measures. The resulting value of $f_{c}$, as measured experimentally, often depends on the initial void volume fraction $f_{0}$. Also, the variation of $f_{c}$ with the stress triaxiality has been investigated by many authors (see, for instance, [5]). It appears that considering $f_{c}$ as constant, for a given material under variable loading and/or different values of $f_{0}$, is a strong assumption. Thanks to Thomason's limit load criterion, a value for $f_{c}$ can be numerically determined, which ensures a continuous and physically-based transition between the stages of growth and coalescence [12]. This criterion is based on the loss of stability of the plastic flow. The onset of coalescence is activated when Thomason's criterion is verified. At this level, $f_{c}$ is fixed to the value of the void volume fraction $f$. It will be shown in this 
paper that the value of $f_{c}$ determined from Thomason's criterion may be quite different from its counterpart experimentally fitted. These differences will be shown either for monotonic or non-monotonic loading paths, as it is the case in deep drawing. These findings are important due to their implications on ductile failure predictions of sheet metals during deep drawing in terms of the critical strain at failure as well as the specific location of the failure zone.

\section{GURSON-TVERGAARD-NEEDLEMAN DAMAGE MODEL}

The constitutive framework of the GTN damage model is described by the following main equations:

- The expression of the GTN yield function:

$$
\Phi_{G T N}=\left(\frac{q}{\bar{\sigma}}\right)^{2}+2 q_{1} f^{*} \cosh \left(-\frac{3 q_{2} p}{2 \bar{\sigma}}\right)-1-q_{3} f^{* 2}
$$

where $q=\sqrt{3 \Sigma_{d}: \Sigma_{d} / 2}$ and $p=-\operatorname{tr}(\Sigma) / 3$ are, respectively, the equivalent macroscopic stress and the hydrostatic pressure associated with the macroscopic stress tensor $\Sigma, \bar{\sigma}$ is the flow stress of the fully dense matrix, $f^{*}$ is the modified volume fraction of voids and $q_{1}, q_{2}$ and $q_{3}$ are material constants. $f^{*}$ is introduced in order to improve the description of the coalescence stage. In this case, one can express $f^{*}$ by using the following empirical equation:

$$
f^{*}=f_{c}+\delta_{G T N}\left(f-f_{c}\right) \text { where } \delta_{G T N}=\left\{\begin{array}{ll}
1 & \text { if } f \leq f_{c} \\
\frac{f_{u}-f_{c}}{f_{F}-f_{c}} & \text { if } f_{c}<f<f_{F}
\end{array} .\right.
$$

In the previous equation, $f_{F}$ represents the final volume fraction prior to failure, while $f_{u}$ is mainly expressed as function of the parameters $q_{1}, q_{2}$ and $q_{3}$ :

$$
f_{u}=\left(q_{1}+\sqrt{q_{1}^{2}-q_{3}}\right) / q_{3} .
$$

- The evolution of the void volume fraction:

The evolution of the void volume fraction is modeled such that the porosity rate $\dot{f}$ is additively decomposed into nucleation and growth parts, denoted $\dot{f}_{n}$ and $\dot{f}_{g}$, respectively

$$
\dot{f}=\dot{f}_{n}+\dot{f}_{g}=\frac{f_{N}}{s_{N} \sqrt{2 \pi}} \exp \left[-\frac{1}{2}\left(\frac{\bar{\varepsilon}^{p}-\varepsilon_{N}}{s_{N}}\right)^{2}\right] \dot{\bar{\varepsilon}}^{p}+(1-f) \operatorname{tr}\left(\boldsymbol{D}^{p}\right),
$$

where $\boldsymbol{D}^{p}$ is the macroscopic plastic strain rate tensor related to $\Phi_{G T N}$ by the normality rule $\boldsymbol{D}^{p}=\dot{\gamma}\left(\partial \Phi_{G T N} / \partial \boldsymbol{\Sigma}\right)$, in which $\dot{\gamma}$ denotes the plastic multiplier. $f_{N}$ represents the volume fraction of inclusions that are likely to nucleate, $\varepsilon_{N}$ refers to the equivalent plastic strain for which half of the inclusions have nucleated, and $s_{N}$ is the standard deviation on $\varepsilon_{N}$.

- The expression of the flow stress $\bar{\sigma}$ of the fully dense matrix, which is defined by the Swift law:

$$
\bar{\sigma}=K\left(\varepsilon_{0}+\bar{\varepsilon}^{p}\right)^{n}
$$

where $\bar{\varepsilon}^{p}$ is the equivalent plastic strain of the fully dense matrix, and $K, n$ and $\varepsilon_{0}$ are hardening parameters.

- The equivalence between the rates of macroscopic and matrix plastic work: 


$$
(1-f) \bar{\sigma} \dot{\bar{\varepsilon}}^{p}=\Sigma: \boldsymbol{D}^{p}
$$

\section{THOMASON COALESCENCE CRITERION}

Thomason's criterion is based on the fact that void coalescence is enabled when the plastic limit load condition is reached for localized deformation of intervoid matrix ([10], [11], [12]). In this paper, voids are assumed to be initially spherical and remain spherical during the deformation. Thomason's criterion states that no coalescence occurs so long as the following condition is satisfied ([14], [15]):

$$
\frac{\Sigma_{\max }}{\bar{\sigma}}<\left(1-\pi \chi^{2}\right) \mathcal{C}_{f}=F(\chi) \quad \text { with } \quad \mathcal{C}_{f}=\left(\alpha(n)\left(\frac{1-\chi}{\chi}\right)^{2}+\frac{\beta}{\sqrt{\chi}}\right) .
$$

In the previous equation, $\Sigma_{\max }$ refers to the maximal principal value of $\boldsymbol{\Sigma}$, while $\alpha(n)$ and $\beta(n)$ are parameters that may depend on the hardening exponent $n$, which ranges between 0 and 0.3 . Pardoen and Hutchinson propose in ([8], [9]) the following expression for $\alpha(n)$ :

$$
\alpha(n)=0.1+0.217 n+4.83 n^{2}
$$

However, parameter $\beta$ is set to 1.24, as suggested by Pardoen and Hutchinson ([8], [9]).

As to $\chi$, which appears in Eq. (7), it refers to the void space ratio, defined as the ratio of the void diameter to the void spacing. The expression of this ratio is given by

$$
\chi=\frac{\left(\frac{6 f}{\pi} \exp \left(\varepsilon_{1}+\varepsilon_{2}+\varepsilon_{3}\right)\right)^{1 / 3}}{\sqrt{\exp \left(\varepsilon_{1}+\varepsilon_{2}+\varepsilon_{3}-\varepsilon_{\max }\right)}},
$$

where $\varepsilon_{1}, \varepsilon_{2}$ and $\varepsilon_{3}$ are the principal macroscopic strains, while $\varepsilon_{\max }$ is equal to $\operatorname{Max}\left(\varepsilon_{1}, \varepsilon_{2}, \varepsilon_{3}\right)$.

\section{NUMERICAL RESULTS}

The constitutive equations presented previously are numerically integrated by using an implicit time integration scheme, as described by Aravas [1], and implemented as a user material (UMAT) subroutine in Abaqus/Standard®) Thomason's criterion is used to determine the value of $f_{c}$. First, the accuracy of the implemented algorithm is evaluated through numerical simulation on a single finite element. Some results from the literature using Thomason's criterion are taken for validation purposes. Then, the simulation results for a uniaxial tensile test obtained by using Thomason's criterion are compared with those associated with a predefined value for $f_{c}$ (fitted on the basis of experimental observations). It will be emphasized that, for a given material, the critical void volume fraction obtained from Thomason's criterion may be significantly different from the predefined $f_{c}$. Finally, finite element modeling of a deep drawing test is performed to show the impact, on the material response, of a predefined value of $f_{c}$ as compared to that computed using Thomason's criterion.

\section{Single finite element simulation}

The aim of this section is twofold: (i) to validate the numerical implementation by comparing the corresponding results with those obtained from the literature, and (ii) to compare the results given by a predefined and a computed value of $f_{c}$, respectively. The material parameters for a 4340 steel material identified in [13] are used in this 
simulation. In the latter framework, the Johnson-Cook hardening model has been adopted for the matrix material [13]. The material parameters of the Swift model are fitted on the basis of the stress-strain curve obtained by the Johnson-Cook hardening model. For the numerical simulation, a single C3D8 finite element is considered for the simulation of the uniaxial tensile test. The loading and boundary conditions are presented in FIGURE 1.

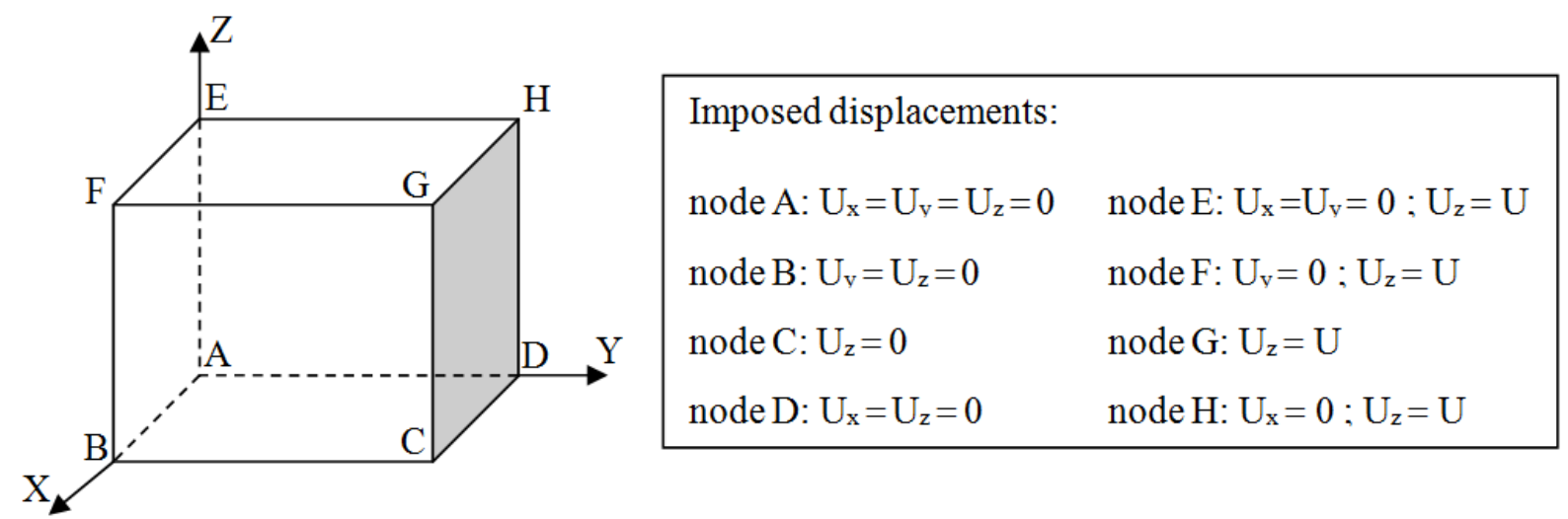

FIGURE 1. Loading and boundary conditions applied to a single finite element.

Our predictions are compared in FIGURE 2 with the results available in [13]. The results are almost indistinguishable. Thomason's criterion permits to predict the onset of coalescence at $f_{c}=0.03$ (see FIGURE 2(c)). FIGURE 2 suggests that some degree of confidence could be accorded to the implemented model, which is able to reproduce the tensile behavior of the 4340 steel material considered.
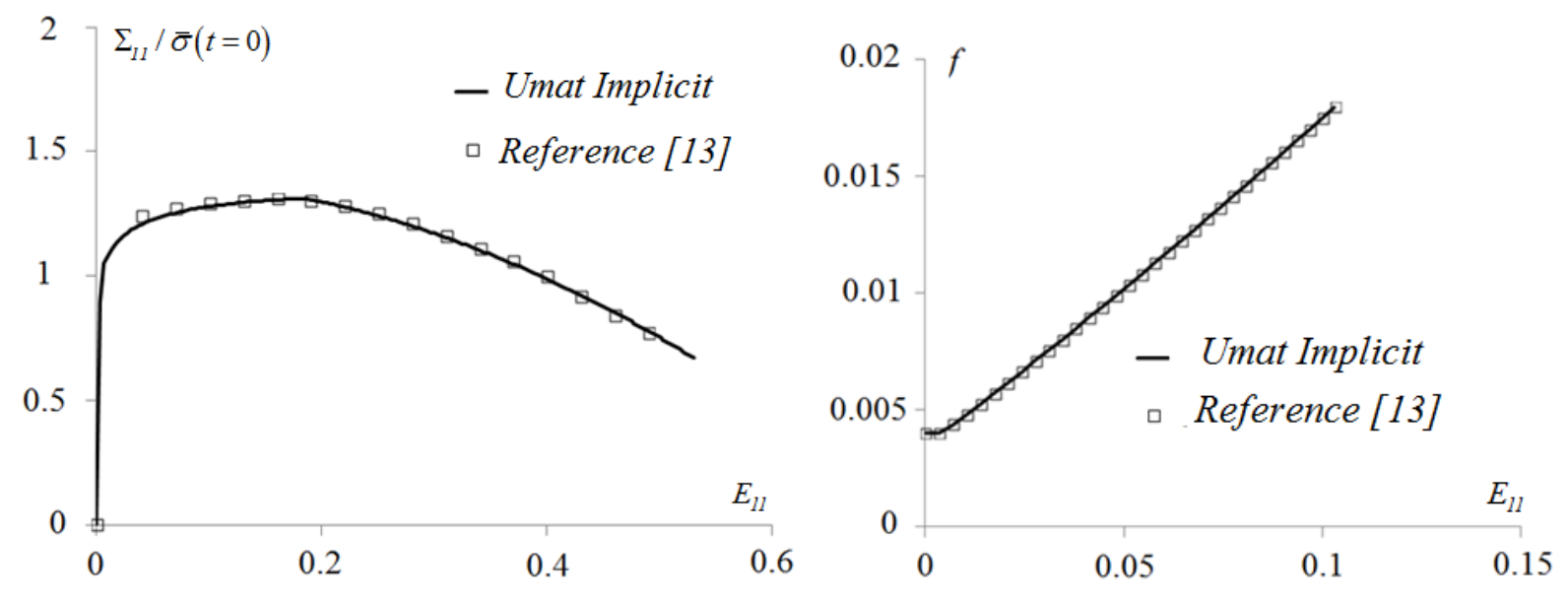

(a)

(b) 


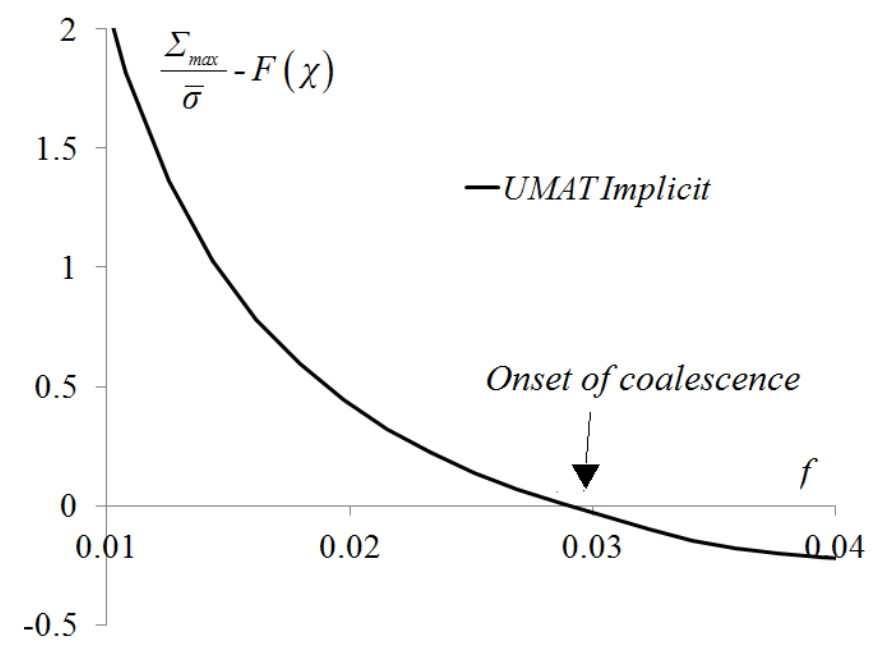

(c)

FIGURE 2. Predictions of the GTN model coupled with Thomason's criterion for a uniaxial tensile test, with comparison to [13].

(a) Stress-strain curves; (b) Evolution of the void volume fraction; (c) Evolution of Thomason's factor $\frac{\sum_{\max }}{\bar{\sigma}}-F(\chi)$.

A second simulation is performed on an Al5182 material, whose associated model parameters are available in ([3], [6]), and summarized in TABLE 1 . The value of the predefined $f_{c}$ is calibrated by using experimental results and is also given in TABLE 1 . In the subsequent simulation, comparisons of uniaxial tensile responses are made to reveal the effect of coalescence initiation modeling (i.e., predefined versus criterion-computed values for $f_{c}$ ). The results of the uniaxial tensile test simulation presented in FIGURE 3 show clear differences between the responses. Whereas $f_{c}$ is predefined as "constant", equal to 0.00213 in the first simulation, a value of $f_{c}$ of 0.027 is found when using Thomason's criterion. It is well known that Thomason's criterion takes into account the relationship between $\chi$ and $f$. The evolution of $\chi$ leads to the translation of the constraint factor $\mathcal{C}_{f}$ involved in the criterion, until the onset of coalescence is predicted ([14]).

TABLE 1. Material parameters for the Al5182 material

\begin{tabular}{rccccccccccccc}
\hline$E[M P a]$ & $v$ & $n$ & $K[M P a]$ & $\varepsilon_{0}$ & $f_{0}$ & $f_{c}$ & $\delta_{\text {GTN }}$ & $q_{1}$ & $q_{2}$ & $q_{3}$ & $s_{N}$ & $\varepsilon_{N}$ & $f_{N}$ \\
\hline 70000 & 0.33 & 0.17 & 371.2 & 0.00324 & $10^{-3}$ & 0.00213 & 10 & 1 & 1.5 & 2.15 & 0.1 & 0.27 & 0.035 \\
\hline
\end{tabular}




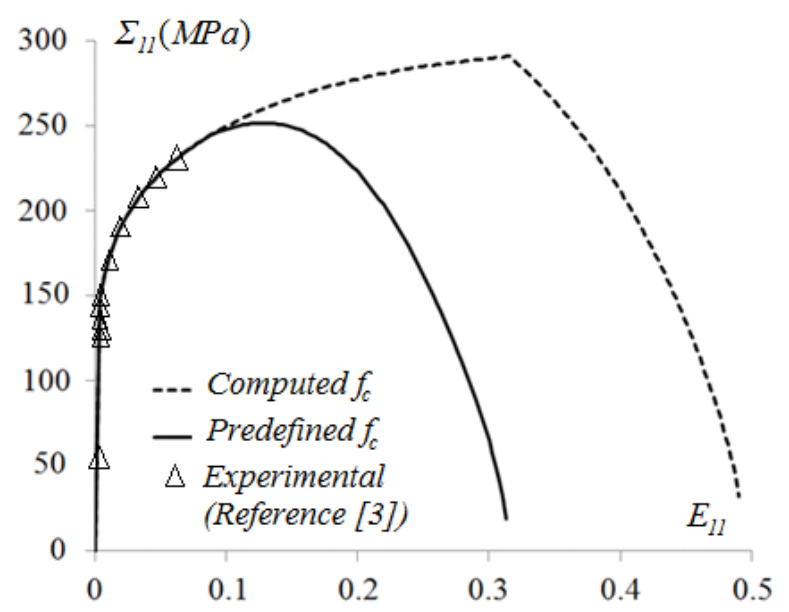

(a)

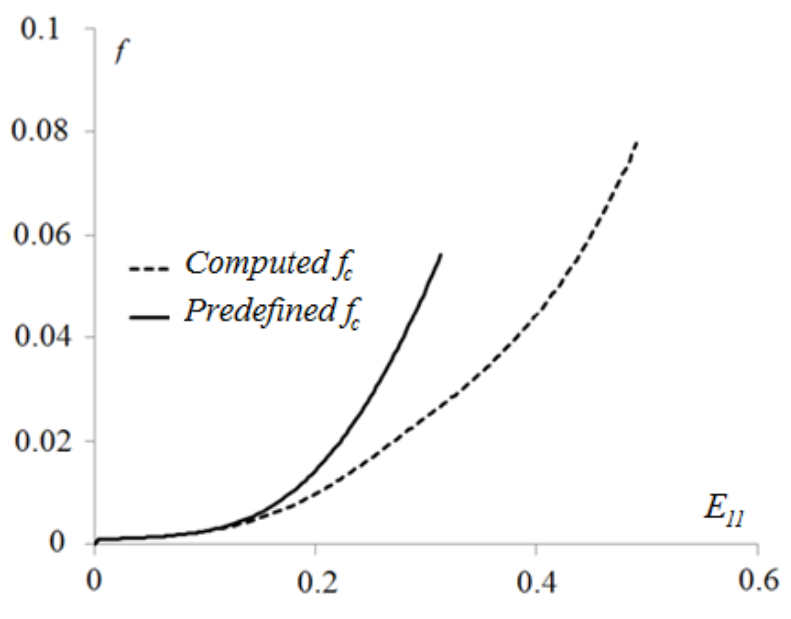

(b)

FIGURE 3. Effect of coalescence initiation modeling (predefined value for $f_{c}$ versus that computed by Thomason's criterion) on: (a) Stress-strain curves, (b) Evolution of the void volume fraction $f$.

\section{Simulation of deep drawing of a cup}

A numerical simulation of deep drawing of an Al5182 metal sheet is performed with the finite element code ABAQUS/Standard using an axisymmetric configuration. The finite element model with its boundary conditions is shown in FIGURE 4. The GTN model with Thomason's criterion is considered in the simulation. The distribution of the void volume fraction in the blank is given in FIGURE 5(a). In this figure, we show that, at this early stage of the process, $f$ has already reached the predefined value of $f_{c}$. FIGURE 5(b) shows the values of Thomason's criterion along the blank. Thomason' criterion must be equal to zero when coalescence is reached. However, as illustrated in FIGURE 5(b), Thomason's criterion is positive and it takes a minimal value of 11.3.

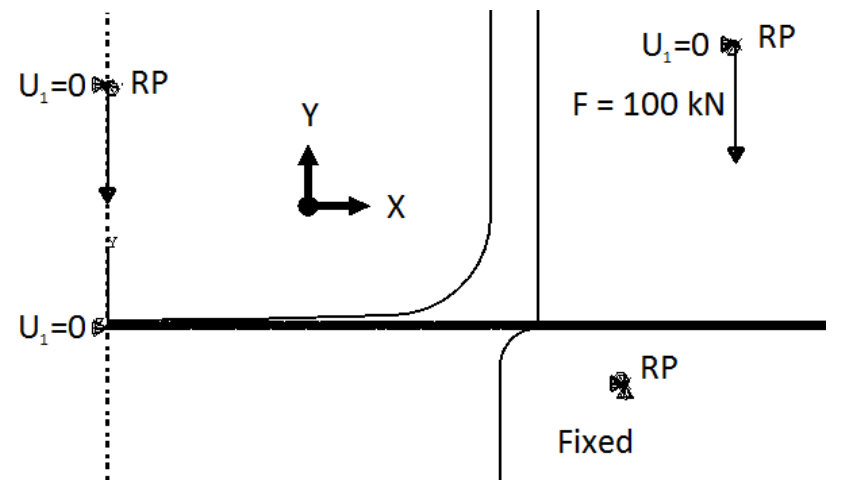

FIGURE 4. Loading and boundary conditions applied in the deep drawing model. 


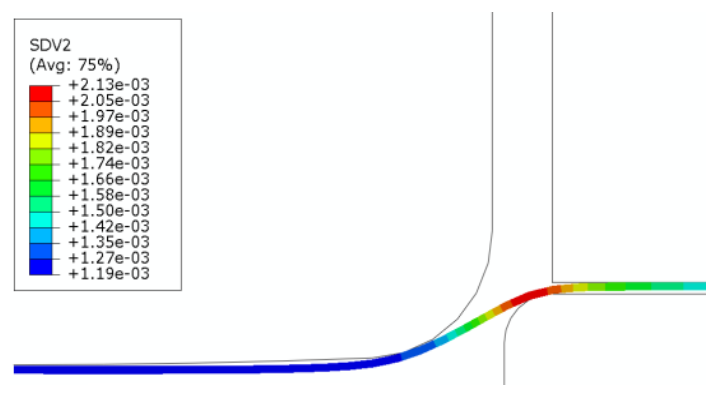

(a)

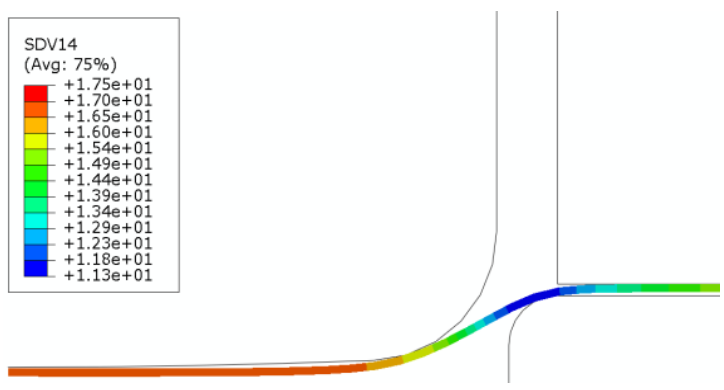

(b)

FIGURE 5. Results of the simulation using the GTN model with Thomason's criterion. (a) $f$ has already reached the predefined value of $f_{c}$. (b) Thomason's criterion is not yet reached at this level.

\section{CONCLUSION}

The GTN model with the embedded Thomason criterion has been numerically integrated and implemented in the finite element code Abaqus. The results of the simulations using a single finite element were compared with some available data and show good repeatability. Other simulations reveal that the value of $f_{c}$ computed by using Thomason's criterion could be quite different from the predefined value of $f_{c}$, as being fitted from experimental stress-strain curves. The predicted value of $f_{c}$ is often higher, which implies a delay in the onset of coalescence. In the same way, the simulation of the deep drawing of a cup indicates that, when $f$ reaches the predefined value of

$f_{c}$, the Thomason criterion is not satisfied yet. These observations confirm the need for precise modeling of the coalescence initiation, as this has significant implications in the prediction of failure during complex material processes, such as sheet metal forming.

\section{REFERENCES}

1. N. Aravas. Int J NumMeth Eng 24, 1395-1416 (1987).

2. M. Ben Bettaieb, X. Lemoine, L. Duchêne, and A.-M. Habraken. Int J Num Meth Eng 85, 1049-1072 (2011).

3. M. Brunet, S. Mguil, and F. Morestin, J Mater Process Tech 80-81, 40-46 (1998).

4. H. Chalal and F. Abed-Meraim, Mech Mater 91, 52-166 (2015).

5. J. Koplik and A. Needleman. Int J Solids Struct 24, 835-853 (1988).

6. L.Z. Mansouri, H. Chalal, and F. Abed-Meraim, Mech Mater 76, 64-92 (2014).

7. A. Needleman and V. Tvergaard. Eng Fract Mech 38, 157-173 (1991).

8. T. Pardoen and J.W. Hutchinson, J Mech Phys Solids 48, 2467-2512 (2000).

9. T. Pardoen, Y. Marchal, and F. Delannay, Eng Fract Mech 69, 617-631 (2002).

10. P.F. Thomason, Acta Metall Mater 33, 1087-1095 (1985).

11. P.F. Thomason, Acta Metall Mater 40, 241-249 (1992).

12. P.F. Thomason, Acta Metall Mater 41, 2127-2134 (1993).

13. G. Vadillo, R. Zaera, and J. Fernãindez-Sãjez, Comput Method Appl M 197, 1280-1295 (2008).

14. Z.L. Zhang and E. Niemi, Eng Fract Mech 48, 529-540 (1994).

15. Z.L. Zhang, C. Thaulow, and J. Odegard, Eng Fract Mech 67, 155-168 (2000). 